Journal of Applied

Ecology 2007

44, 1086-1088

FORUM

\title{
The kangaroo conundrum remains
}

\author{
KAREN L. VIGGERS* and DAVID B. LINDENMAYER †† \\ *Brudine Veterinary Hospital, 1 Alfred Hill Drive, Melba, ACT 2615; and $\dagger$ Centre for Resource and Environmental \\ Studies, The Australian National University, Canberra, ACT 0200, Australia
}

\section{Summary}

1. The management of kangaroo populations is a major land management and conservation issue in many parts of Australia.

2. Viggers \& Hearn (2005) reported the results of a substantial radio-tracking study of the eastern grey kangaroo (Macropus giganteus Shaw) in south-eastern Australia. Martin et al. (2007) critique the study design, home range analysis, biomass assessment and other aspects of the work by Viggers \& Hearn (2005).

3. We reject the criticisms made by Martin et al. (2007) and believe that the study design employed by Viggers \& Hearn (2005) was sound. The work also was preceded by extensive day and night-time field assessments to enable contrasts between low and high density M. giganteus populations. We also contend that the home range analysis was not flawed: the methods employed by Viggers \& Hearn (2005) were in fact the same ones recommended by Martin et al. (2007). We believe that other criticisms made by Martin et al. (2007) also cannot be sustained.

4. Synthesis and applications. Viggers \& Hearn (2005) found that patches of remnant native vegetation were used as day and night-time refuges by $M$. giganteus. This creates a disincentive for farmers to conserve remnant native vegetation. The criticisms by Martin et al. (2007) have no bearing on this conclusion; hence the kangaroo conundrum stands.

Key-words: animal movement, eastern grey kangaroo, home range analysis, Macropus giganteus, remnant vegetation, study design, kangaroo biology.

Journal of Applied Ecology (2007) 44, 1086-1088

doi: 10.1111/j.1365-2664.2007.01365.x

\section{Introduction}

Viggers \& Hearn (2005) describe the results of a substantial radio-tracking study of the eastern grey kangaroo (Macropus giganteus) in the Australian Capital Territory (ACT), south-eastern Australia. Martin et al. (2007) critique Viggers \& Hearn (2005) on several grounds. We believe their criticisms are ill-founded, have been made without any attempt to seek further details from Viggers \& Hearn (2005) concerning the basis for the investigation and that, most importantly, they make no difference to the overall outcomes. Hence, the kangaroo-remnant native vegetation conundrum stands.

\section{Study design}

Martin et al. (2007) made several criticisms of the study design of Viggers \& Hearn (2005). They argue that rep-

(C) 2007 The Authors. Journal compilation (C) 2007 British Ecological Society lication of land uses was required, but the nature of the

\$Author for correspondence: davidl@cres.anu.edu.au Fax: \pm 61261250757 environment in the ACT region made it impossible to find replicate sites. This was the reason why the study by Viggers \& Hearn (2005) was a descriptive investigation and the unit of observation and analysis was not a 'site' or 'land use', but rather an individual animal. The study by Viggers \& Hearn (2005) was guided by expert statistical advice from two professional consultant statisticians. We believe that Martin et al. (2007) may not understand the difference between descriptive studies, observation studies, natural experiments, and true experiments.

In the study by Viggers \& Hearn (2005), individual animals were radio-tracked in areas subject to different land uses. In contrast to criticisms made by Martin et al. (2007), Viggers \& Hearn (2005) did not attempt to extrapolate beyond the limits of the design at all - it would be entirely inappropriate and statistically invalid to do so.

Criticism that Viggers \& Hearn (2005) 'referred to farms ... in the plural, despite the fact that they studied only one farm site' suggest that Martin et al. (2007) failed to read the methods closely. The farm study sites 
1087

Movements of

eastern grey

kangaroos
(C) 2007 The Authors. Journal compilation (C) 2007 British Ecological Society, Journal of Applied Ecology, $\mathbf{4 4}$ $1086-1088$ referred to in Viggers \& Hearn (2005) encompassed the Cotter farm, as well as the farm immediately adjacent to the Googong reserve onto which kangaroos were tracked and where pasture biomass estimates also were made.

\section{Population density}

We believe Martin et al. (2007) make inappropriate criticisms about the classification of population densities at the study sites used by Viggers \& Hearn (2005). Viggers \& Hearn (2005) made careful assessments of population density not only on the basis of earlier information collated by the Kangaroo Advisory Committee 1996), but also based on advice from leading experts in the ACT region. This was followed by repeated and prolonged site-based day and night-time assessments that preceded the commencement of their study. The key aim of the pre-study assessment was not to obtain accurate estimates of absolute abundance. Rather, it was to ensure that study populations that exhibited high (i.e. low vs. high) contrast in relative animal density were identified. This is a well known and widely applied statistical approach in descriptive studies when absolute measures of abundance are difficult if not impossible to obtain.

\section{Home range estimates}

Martin et al. (2007) outline concerns about home range analyses of Macropus giganteus. We believe there is little substance to sustain their arguments. It is well known that home range research is largely descriptive and that different methods of home range analysis will yield somewhat different results (White \& Garrot 1990). Martin et al. (2007) acknowledge that the kernel density estimators used in the study by Viggers \& Hearn (2005) are among the best methods for estimating home range.

Home range analysis (including the selection of the smoothing factor) by Viggers \& Hearn (2005) was guided by the instructions accompanying the Animal Movement Extension (Version 2.04) (Hooge, Soloman \& Eichenlaub 1999) of the ARCView Spatial Analyst 2.1a Geographic Information System (ESRI R, Redlands, CA, USA), which was current at the time of writing the paper. In that package, the instructions clearly stated that the Least Squares Cross Validation (LSCV) provided the best choice of smoothing factor, and so this approach was used in the study by Viggers \& Hearn (2005). This also was the method of selection of smoothing factor recommended by Martin et al. (2007) in their critique of Viggers \& Hearn (2005).

To determine the minimum sample size of locations to include in analyses, incremental area analysis was used by Viggers \& Hearn (2005) and a clear asymptote in the relationship between the number of fixes and home range size was reached for each individual. Notably, although data from animals with a minimum of 30 fixes were included in the analyses, 60-96 fixes were obtained for the majority of individuals. Interestingly, although the data presented by Martin et al. (2007) were based on repeat locations from only four animals, their findings for home range size and shape and the internal distribution of locations were similar to those reported in Viggers \& Hearn (2005). This is why the method of incremental area analysis was used - so that greater effort could be expended acquiring data from more animals, rather than accumulating more data for a few animals that would have resulted in little difference to the overall home range size. Given that the purpose of the study by Viggers \& Hearn (2005) was to examine movements of animals between farmlands and reserves, it was considered important to reduce sampling intensity at the animal level in order to increase the number of animals sampled, because the animal was the unit of observation. This was a statistical decision and its validity is vindicated by the fact that: (1) an asymptote was reached, and (2) Martin et al. (2007) achieved similar results with 95-122 locations.

Viggers \& Hearn (2005) well understood the limitations of radio-tracking data, home range analysis, and issues with sample size influencing home range area (i.e. under-estimation at low sample sizes). However, the standard best approach to choosing the smoothing factor was applied, incremental area analysis was used to obtain an asymptote for selection of minimum sample size, and no extrapolations were made beyond the scope of the data. In summary, we believe the criticisms made by Martin et al. (2007) regarding the home range analysis cannot be sustained.

\section{Resource availability}

Viggers \& Hearn (2005) were criticised by Martin et al. (2007) for the way they measured pasture availability. We suspect this criticism was made without any apparent knowledge of pasture and other conditions in the ACT study areas. Viggers \& Hearn (2005) clearly outlined the methods they used to sample biomass at 720 randomly distributed plots in each of the three study sites. The 8640 plots targeted areas where animals had been routinely observed both resting and grazing.

Pasture biomass was used as a broad measure of pasture availability. Viggers \& Hearn (2005) were acutely aware that species composition and abundance would have varied between the study sites. However, grazing was the predominant land-use at all sites, and all areas used by kangaroos for grazing contained predominantly exotic pasture species and some native species. Importantly, pasture cover was measured in the same way by the same observer at each site. It was not within the scope of the study by Viggers \& Hearn (2005) to detail floristic composition or protein levels of pasture over the many plots that were used to estimate pasture biomass. In addition, it should be noted that the methods used in this study to broadly estimate pasture biomass are widely used in agricultural studies. Therefore, as a broad estimate of pasture biomass, we believe that the approach of Viggers \& Hearn (2005) was valid. The 
1088

K. L. Viggers \&

D. B. Lindenmayer fact that kangaroos are predominantly grazers (Taylor 1983) was the reason why pasture biomass was estimated as a broad measure of food availability by Viggers \& Hearn (2005).

\section{Kangaroo biology}

Martin et al. (2007) claim that Viggers \& Hearn (2005) did not understand the biology of $M$. giganteus. We disagree. The study was based on information from a wide range of studies from around Australia, together with considerable local knowledge of the species accumulated over more than a decade of research and monitoring.

We believe that Martin et al. (2007) make unjustified criticisms of Viggers \& Hearn (2005) for not presenting analyses of relationships between home range and culling, sex, age and reproductive status. This was because there were insufficient data to do so and Viggers \& Hearn (2005) did not wish to extrapolate beyond the limits of their data. Moreover, tackling questions associated with the impacts of culling would require a different study and study design. Viggers \& Hearn (2005) were aware that culling may have affected movements of those animals on the Cotter farm which were exempt from culling. On-ground observations suggested that this was not the case. However, Viggers \& Hearn (2005) did not discuss this issue in detail given that the sample size of collared animals at that site was small.

We argue that semantics about terminology presented by Martin et al. (2007) were not correct and make no difference to the findings of the study by Viggers \& Hearn (2005). At no stage do Viggers \& Hearn (2005) associate dispersal with daily movements of kangaroos; rather the term was used to apply to long-range permanent movements. Examples provided by Martin et al. (2007) of dispersal events frequently involving individuals passing through suboptimal habitat are not for macropods.

\section{Conclusions}

We believe that the home range data and analysis were not flawed, the pasture measurements and analyses were valid at the scale required for this study, and the biology of the species was well understood. We contend that the issues Martin et al. (2007) raise can be readily refuted, and perhaps more significantly they make no difference to the key management conclusions. Private landholders are deeply concerned about large macropods because they consume pasture plants and shelter in patches of remnant native vegetation. This leaves landholders with little incentive to retain remnant vegetation on their farms. This finding has recently been confirmed in a major study of on-farm biodiversity and landholder attitudes in which over 50 private property owners across southern New South Wales (in southeastern Australia) were surveyed (see Cunningham et al. 2007). Hence, the logical conclusion is that the kangaroo conundrum stands and indeed it remains as equally valid now as it was in the paper by Viggers \& Hearn (2005).

\section{Acknowledgements}

We thank Adjunct Professor Ross Cunningham and Associate-Professor Jeff Wood for assistance in the design and analysis of the original study and comments on this paper.

\section{References}

Cunningham, R.B., Lindenmayer, D.B., Crane, M., Michael, D. \& MacGregor, C. (2007) Reptile and arboreal marsupial response to replanted vegetation in agricultural landscapes. Ecological Applications, 17(2), 609-619.

Hooge, P.N., Solomon, E. \& Eichenlaub, B. (1999) Animal Movement Program. Alaskan Biological. Research Center, Anchorage, Alaska.

Kangaroo Advisory Committee (1996) Living with Kangaroos in the ACT: Rural Lands. First Report to the Minister for the Environment, Land and Planning, Canberra, Australia.

Martin, J.K., Coulson, G., Di Stefano, J., Ritchie, E.G., Greenfield, A., Catanchin, H. \& Evans, L.N. (2007) The Viggers \& Hearn conundrum: a kangaroo home range study with no implications for land management. Journal of Applied Ecology, 44, in press.

Taylor, R.J. (1983) The diet of the eastern grey kangaroo and wallaroo in areas of improved and native pasture in the New-England tablelands. Australian Wildlife Research, 10, 203-211.

Viggers, K.L. \& Hearn, J.P. (2005) The kangaroo conundrum: home range studies and implications for land management. Journal of Applied Ecology, 42, 99-107.

White, G.C. \& Garrot, R.A. (1990) Analysis of Wildlife RadioTracking Data. Academic Press, San Diego, California.

Received 20 March 2007; final copy received 6 June 2007 Editor: Christopher Dickman
C 2007 The Authors. Journal compilation (C) 2007 British Ecological Society, Journal of Applied Ecology, 44, 1086-1088 